\title{
$\operatorname{arCOS} D E S I G N$
}

\section{Uma abordagem sobre os conceitos de interatividade e sua relação com o design}

Natália Ordobás Bortolás (UFSC, Brasil)

nbortolas@gmail.com

Campus Universitário Reitor João David Ferreira Lima

Trindade, Florianópolis, SC, Brasil CEP: 88040-970

Milton Luiz Horn Vieira (UFSC, Brasil)

milton@cce.ufsc.br 


\section{Uma abordagem sobre os conceitos de interatividade e sua relação com o design}

Resumo: Este artigo propõe abordar conceitos sobre Interatividade e relacioná-los com o Design de Interface, sob uma perspectiva tecnológica e comunicacional. O embasamento teórico foi fundamentado a partir dos conhecimentos de Steuer (1992), Jensen (1998) e Kiousis (2002). As relações entre Interatividade e Design puderam verificar que a Interatividade é um tópico da comunicação digital que está inserido no processo de criação de interfaces digitais e, assim, intimamente relacionado ao Design.

Palavras-chave: Interatividade, Design, Interface Digital.

\section{An aproach over the interactivity's concepts and its relation with design}

Abstract: This article proposes to approach concepts of Interactivity and relate them to the Design Interface, under a technological and communicational perspective. The theoretical framework was based on Steuer (1992), Jensen (1998) and Kiousis (2002). Relations between Interactivity and Design could verify that Interactivity is a topic of digital communication that is inserted into the process of creating digital interfaces and thus closely related to Design.

Key words: Interactivity, Design, Digital Interface. 


\section{Introdução}

Na concepção de produtos virtuais, a interface digital é um elemento central. Parte disso deve-se à disseminação da informática, com o crescente uso de computadores pessoais, smartphones e tablets, além da expansão da área de Web Design (REDIG, 2004). Certamente, ainda de acordo com o autor, o crescente valor da informação também ajudou a propiciar esse cenário.

As tecnologias em formato digital são produtos de interação com os seres humanos. De certa forma são também extensões do corpo humano, pois são criadas por ele a fim de otimizar suas atividades diárias, seja no campo profissional, pessoal, acadêmico etc. A tecnologia em formato digital permite que os meios de comunicação atinjam o usuário, de modo que ele obtenha uma resposta imediata. Assim, a Interatividade é um tópico fundamental da comunicação digital (sANTAELla, 2004).

Nesta ótica, o presente artigo buscou abordar os principais conceitos da Interatividade a fim de relacioná-los com o Design de interfaces digitais. Este trabalho é parte de um projeto com foco em ambientes digitais hipermidiáticos, que pretende avaliar o protótipo de um sistema, a partir das suas características e elementos interativos. Assim, verifica-se a necessidade de definir a relevância do estudo do Design nas Mídias Interativas.

Percebe-se que a Interatividade, no contexto do projeto de interfaces digitais, é pouco abordada e que a importância de sua aplicação em projetos desse tipo é subestimada. Ao ignorar a Interatividade como uma característica fundamental da comunicação digital, há perda na qualidade de produtos digitais, além do funcionamento precário de sistemas computacionais.

Cabe ainda ressaltar uma incoerência entre o termo Mídia Interativa utilizado para definir alguns produtos tecnológicos e suas características, que nem sempre incluem a interatividade. A definição precisa da relação entre Design e Interatividade poderia contribuir para entender esses desvios e buscar meios para solucioná-los.

Numa outra perspectiva, tecnologias digitais são bastante estimadas e utilizadas em diversos ramos por certas razões, dentre as quais:

- Diminuem o tempo de realização de tarefas, como fazer uma compra online ou enviar mensagens textuais;

- São consideradas extensões do corpo humano por realizarem tarefas que antes eram feitas apenas pelo homem (de forma mais lenta), como executar cálculos, desenvolver projetos e controlar máquinas;

- São ferramentas que buscam prevenir falhas que poderiam ocorrer se o processo fosse realizado totalmente por seres humanos. Sistemas 
Operacionais de Transporte, sejam aéreos, ferroviários, rodoviários ou marítimos, são projetados para corrigir falhas que poderiam ser por eles causadas.

Entende-se, então, que existe um contraponto entre o impacto que as tecnologias digitais causam no cotidiano das pessoas e a seriedade com que estes produtos devem ser desenvolvidos. Assim, com o intuito de usufruir do potencial que as interfaces de tecnologias digitais proporcionam, denota-se a necessidade de avaliar as qualidades básicas das interfaces gráficas do usuário, sendo uma delas, a Interatividade.

Para definir conceitos de Interatividade que se relacionam com o Design de Interfaces, utilizou-se a perspectiva tecnológica e, em segundo plano, a comunicacional. Os principais autores que conceituam a Interatividade sob uma perspectiva tecnológica e que foram a base para as definições aqui tratadas são Steuer (1992), Jensen (1998) e, principalmente, Kiousis (2002). Da mesma forma, eles tratam o assunto sob uma perspectiva comunicacional, pois a pesquisa tendo como base a Interface Gráfica do Usuário (GUI) implica também no estudoda comunicação digital nesse ambiente.

O Design é Comunicação Visual e, no que tange ao Design de Interfaces Digitais, ele tem relação direta com a comunicação digital, pois é a atividade que busca compreender e definir os elementos interativos da GUI, facilitando a interação humano-computador. Os principais autores que abordaram conceitos do Design foram Bonsiepe (1997), Coelho (2008) e Reginaldo e Perassi (2012). Os conceitos de Cruz (2008) também foram essenciais nas definições para a atividade do Design de Interface.

A abordagem dos conceitos de Interatividade a partir de uma perspectiva tecnológica e comunicacional, bem como o levantamento de conceitos fundamentais do Design, possibilitou relacionar a qualidade primordial de Mídias Interativas - a Interatividade - com a atividade do Design, inferindo-se que a primeira é tarefa essencial do processo de Design de Interfaces.

\section{Interfaces e sistemas}

De acordo com a Porto Editora (2012), dicionário mobile da Língua Portuguesa, a palavra "interface" apresenta os seguintes significados: "1. Dispositivo de ligação entre sistemas"; 2. Elemento de ligação de dois ou mais componentes de um sistema"; 3. INFORMÁTICA modalidade gráfica de apresentação dos dados e das funções de um programa". 
No Dicionário Aurélio (2008), a palavra interface é definida como:

1. sf. Recurso que permite comunicação ou interação entre dois sistemas ou organismos; 2. Inform. Dispositivo de conexão entre computador e periférico(s), ou entre periféricos; 3. Inform. Conjunto de elementos de hardware e software destinados a possibilitar a interação com o usuário.

Os conceitos apresentados sobre o verbete "interface", relacionando-o frequentemente a um objeto ("dispositivo", "elemento" ou "conjunto de elementos", "modalidade gráfica de apresentação"), apresentam um caráter tecnicista, ou seja, que estão voltados a características tecnológicas de hardware e software. Da mesma forma, alguns autores (BATISTA, 2008; CRUZ, 2008; PASsos, 2010) definem a interface como um objeto físico de interação entre computador e usuário.

Por outro lado, mesmo existindo uma relação forte da palavra interface com o objeto físico e palpável que permite a interação humano-computador, alguns autores defendem um conceito mais aprofundado e bastante relacionado com o Design. Para Bonsiepe (1997), Braga (2004) e Bevilácqua (2007), interface é o espaço onde se estrutura a interação. É o meio que propicia ao usuário usar uma ferramenta e realizar uma ação.

Para Bonsiepe (1997), no esquema do Design existem três âmbitos unidos que necessitam de uma categoria central. Estes três âmbitos são: 1. um usuário ou agente social, que deseja cumprir uma ação; 2 . uma tarefa que o agente social deseja executar; e 3. um utensílio ou artefato do qual o agente precisa para levar a termo a ação. A categoria central desses três âmbitos é o que as conecta: é a interface. O utensílio ou artefato é a ferramenta usada para realizar a ação e a interface é o fator essencial do utensílio (вONSIEPE, 1997). A Figura 1 ilustra o conceito de Bonsiepe, no entanto, com exemplo adaptado para o foco deste trabalho.

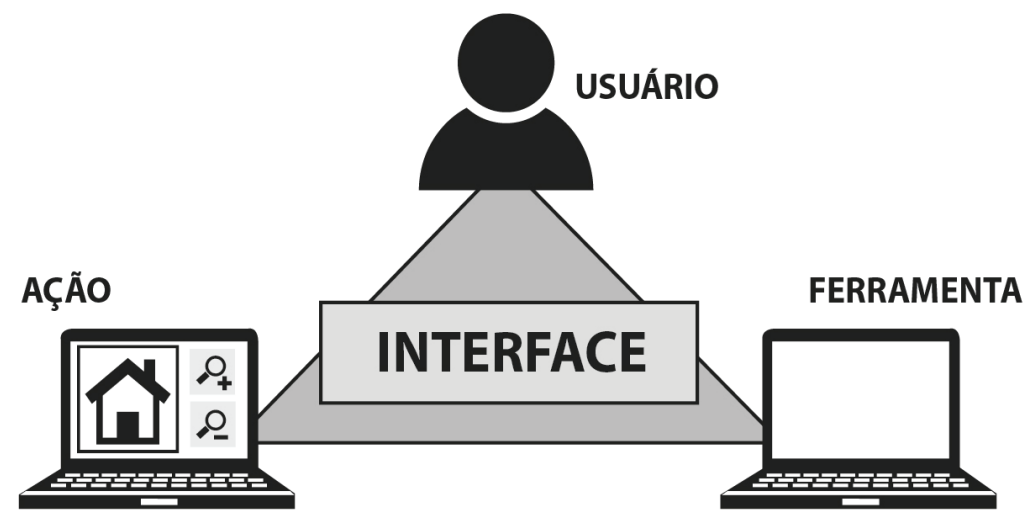

Figura 1. Definição de Interface adaptada de Bonsiepe (1997). 
Considerando a associação que o termo interface tem com as novas tecnologias (notebooks, smartphones, tablets etc.), foi criada a GUI (Graphical User Interface ou Interface Gráfica do Usuário). A Interface Gráfica do Usuário, ou simplesmente Interface, de acordo com Braga (2004), tem como função ser o ponto de interconexão entre o usuário e a tecnologia. Os usuários, por sua vez, têm o controle das diversas funções (armazenar dados, transmitir informações etc.) destas tecnologias graças à GUI.

Assim, a Interface Gráfica do Usuário passa "da função de ponto de interconexão entre usuário e tecnologia, para um sistema de interação entre homem e máquina”, e o que explica as funções de qualquer interface humano-computador é a definição de sistemas (BRAGA, 2004, p. 10).

Os conceitos encontrados e aqui explicitados sobre sistema são genéricos. Para Moraes e Mont'Alvão (2010), o significado de sistema tem proximidade com as ideias de organização, relação e objetivo final. Diz respeito à relação, pois sistema é um conjunto de elementos (BRAGA, 2004), entre os quais deve ter uma relação ou uma dependência entre si. É, então, um conjunto de partes interagentes, pois "implica que a modificação em uma ou mais resulta na alteração em pelo menos uma outra parte do todo" (MORAES; MONT'ALVÃo, 2010, p.35).

O conceito de sistema também diz respeito à organização, pois ele é a disposição das partes ou dos elementos de um todo, coordenados e formando uma estrutura organizada (DICIONÁrio AURÉLIO, 2008). Complementam Moraes e Mont'Avão (2010) que a ideia de organização é inerente ao sistema, pois busca o equilíbrio, indo a favor da anamorfose (sistema que tende ao desenvolvimento, à organização crescente).

Os sistemas também buscam atingir um determinado fim, sendo que a relação entre as partes vai ao encontro de um objetivo final (MORAES; MONT'ALVÃo, 2010). Na mesma linha de pensamento das autoras, Braga (2004) diz que o conceito de sistemas envolve a sinergia, a integração e a interatividade. A sinergia diz respeito aos elementos com ações que buscam um mesmo objetivo, a integração é quando a alteração de um elemento ocasiona a alteração de um, de vários elementos ou até mesmo de todo o sistema. A interatividade envolve os elementos que interagem e atuam a partir da comunicação entre eles. 


\subsection{Interface Web: Um Sistema Online}

Considerando uma interface web (seja um site ou aplicativo) como um sistema a ser construído, pode-se deduzir que existem duas grandes áreas a se conhecer para desenvolvê-lo. A primeira é o Design de Interfaces, que vai possibilitar a interação entre usuário e dispositivo, e a segunda é o Desenvolvimento Web, que trabalha com a programação das tarefas e funcionalidades, além de marcações das páginas web. A Figura 2 apresenta os sistemas e o que contempla cada um deles.

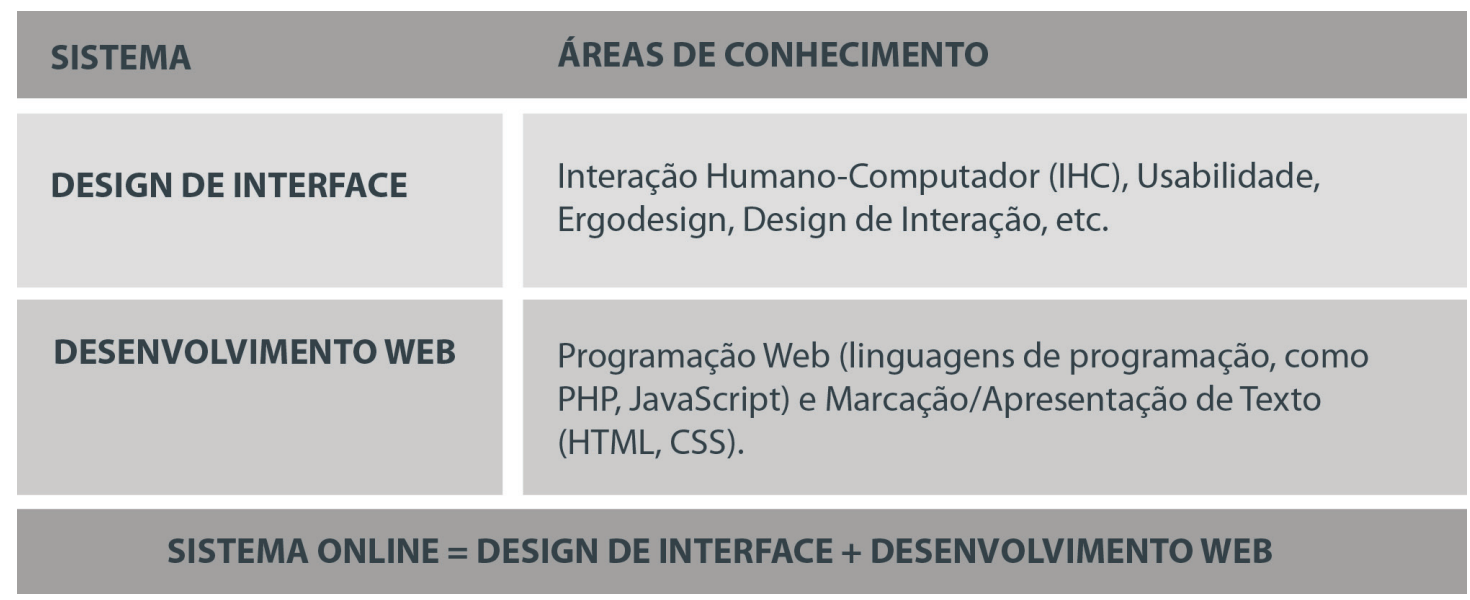

Figura 2. Formação de um Sistema Online

Entende-se, então, que um sistema online é o produto criado pelo Design de Interface junto ao Desenvolvimento Web. Um depende e relaciona-se com o outro para desenvolver um sistema.

\section{Design de Interface}

Para definir o conceito de Design de Interface, é fundamental definir, antes, o conceito de Design. Segundo as palavras de Coelho (2008), Design:

É um campo amplo de atividades (desempenho) especializadas, de caráter técnico e científico, criativo e artístico que se ocupam em organizar, classificar, planejar, conceber, PROJETAR, configurar, sistemas de INFORMAÇÃo, objetos bidimensionais (gráficos), tridimensionais (volumétricos), virtuais, ambientes ou espaços para a PRODUÇão industrial e/ou artesanal (COELHo, 2008, p. 188). 
As atividades descritas do Design também levam em consideração as "questões de uso, FUNÇÃo (objetiva ou subjetiva), produção, MERCADO, UTILIDADE, QUALIDADE, fatores sociais, culturais, antropológicos, ecológicos, ergonômicos, tecnológicos e econômicos" (COElho, 2008, p.188).

É de competência da área de design o projeto de formas ou mensagens não verbais, investindo características estéticas, semânticas e funcionais, que habilitam o produto para cumprir as funções de atração, significação e utilização. (REGINALDO; PERASSI, 2012, p. 421).

O processo de Design gera um produto que se relaciona diretamente com o consumidor e tal relação tem aspectos essenciais (silveira et al, 2010). De acordo com Löbach (2001), estes aspectos essenciais contemplam três funções do produto: a Função Prática, Função Simbólica e Função Estética.

No que tange a essas três funções, há uma diferenciação entre produtos tridimensionais e gráficos ou digitais. A função prática dos produtos tridimensionais podem determinar a sua qualidade e, tal função, trata especificamente da funcionalidade dos produtos (sILVEIRA ET AL., 2010). Complementa Löbach (2001), que a função prática relaciona-se, principalmente, às necessidades fisiológicas do usuário.

"Em design gráfico, a função simbólica coincide com a função prática dos produtos [tridimensionais], considerando-se que o objetivo central é informar e comunicar, independente da natureza do produto gráfico" (ALMEIDA, 2012).

Considera-se que o Design gráfico utiliza as mídias impressas (revistas, jornais, dentre outros) como plataforma para as suas atividades, bem como o Design digital utiliza as mídias digitais (computadores pessoais, smartphones etc.) para as suas. Infere-se, então, que nenhuma das duas atividades tem como intuito desenvolver produtos tridimensionais tangíveis, fazendo com que sua atividade principal seja a informação e a comunicação.

Reginaldo e Perassi (2012, p.241) sugerem que "o objeto de estudo específico do Design é a 'forma', sua atividade é a 'informação', composta e apresentada como objeto, e sua finalidade é o 'produto'." Tal conceito abrange qualquer área do Design, seja no desenvolvimento de produtos tridimensionais, gráficos ou digitais. Porém, particularmente no caso de produtos digitais, o fator informação é preponderante, pois a tangibilidade, as sensações palpáveis, não estão presentes.

Para Bonsiepe (1997), Design tem como foco a interação entre usuário e artefato, como forma de domínio da interface. Löbach (2001) concorda com Bonsiepe ao sugerir que o Design deve atuar constantemente na defesa dos 
interesses do usuário.

A respeito do conceito de Design de Interfaces, pode-se entender que o enfoque dessa atividade remete às novas tecnologias digitais, mesmo que o termo Interface possa referir-se a qualquer tipo de produto, pois, como sugere Bonsiepe (1997), interface é o espaço onde se estrutura uma interação entre agente social e ferramenta utilizada pelo agente, independente de qual seja essa ferramenta.

No Brasil, os termos 'projeto de interface' e 'design de interface' são utilizados pela literatura especializada para se referenciar ao desenvolvimento de interfaces. Isto é consequência das diferentes traduções apresentadas para o termo 'design', já que grande parte da literatura relacionada a este tema se origina no exterior (CRUZ, 2008, p. 38-39).

Para Cruz (2008, p. 38) o design/projeto de interfaces se responsabiliza por desenvolver projetos e possibilitar a interação entre usuários e sistemas, "envolvendo a definição de padrões visuais e funcionais, além do planejamento de estruturas voltadas ao acesso e à execução de tarefas em mídias interativas".

A interface gráfica do usuário é composta por um conjunto de elementos que tornam possível o usuário ver, ouvir e interagir com as informações (ватіsтA, 2008). A autora dividiu tais elementos nas seguintes classificações: Elementos textuais, Elementos não-textuais (imagens estáticas e animadas, vídeos e áudio), Elementos de Leiaute (página/tela, templates, cores, fontes, linhas, arranjo/diagramação), Elementos Interpretáveis por Navegadores (html e css) e Elementos Interativos. A Figura 3 é baseada na estrutura de elementos de interface criada por Batista (2008) e compreende a classificação de Elementos Interativos. 


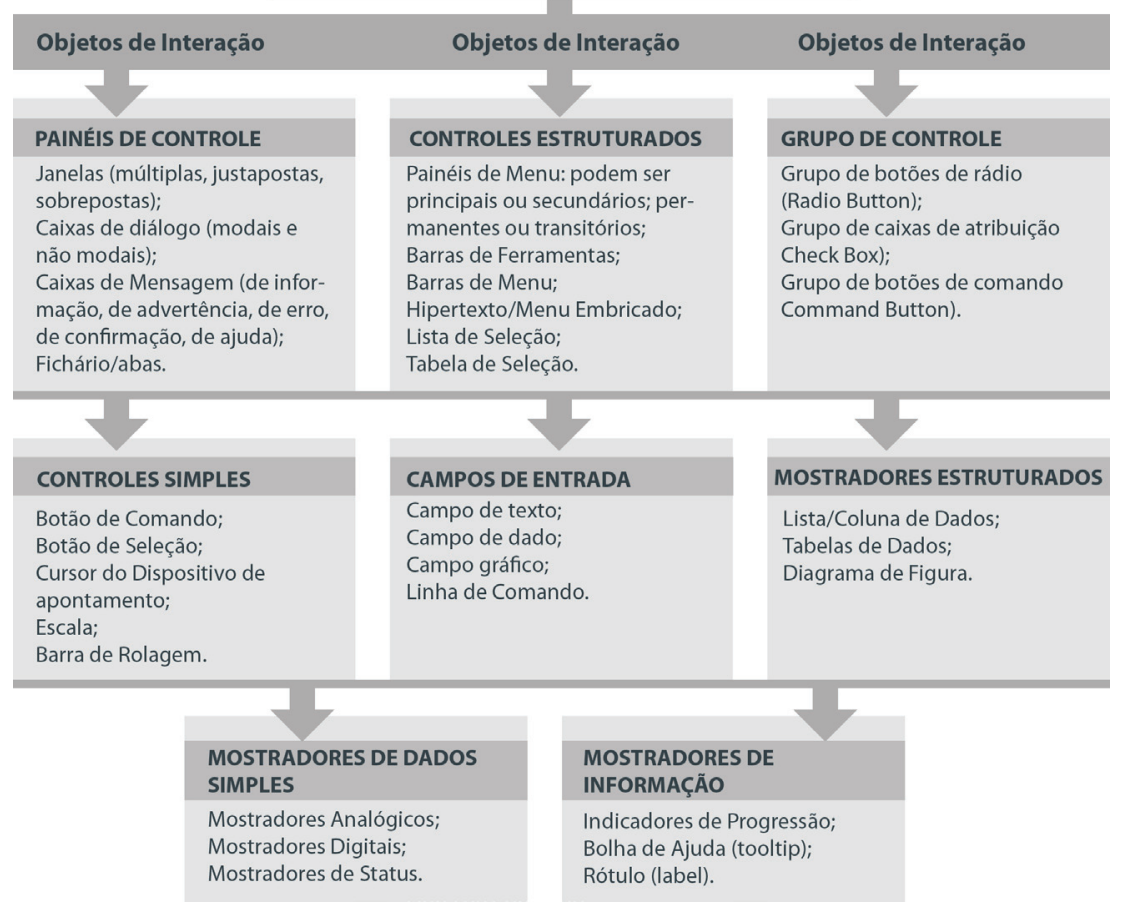

Figura 3. Elementos Interativos da Interface Gráfica do Usuário adaptado de Batista (2008)

Entende-se, então, que o foco principal do Design de Interface é proporcionar interação entre o usuário e a GUI, para que haja comunicação entre as duas partes a partir dos elementos gráfico-visuais (cores, imagens, textos) e, principalmente, dos elementos interativos.

Coelho (2008) ressalta as questões de uso e de utilidade como características a serem levadas em consideração no Design. Reginaldo e Perassi (2012) também sugerem que é de competência da área do Design habilitar um produto para as funções de utilização.

Questões de uso e utilidade referem-se à usabilidade dos produtos e esta é uma característica bastante pesquisada na área de Design, principalmente no Design de Interfaces, como apresentam em suas obras Cybis, Betiol e Faust (2010), Krug (2008), Preece, Rogers e Sharp (2005), Memória (2005), dentre outros.

Para Cybis, Betiol e Faust (2010, p. 16), a usabilidade "é [...] uma composição flexível entre aspectos objetivos, envolvendo a produtividade na interação, e subjetivos, ligados ao prazer do usuário em sua experiência com o 
sistema". "Como conceito, a usabilidade trata da ADEQUAÇÃO entre produto e as tarefas a cujo desempenho se destina, da adequação como o usuário o utilizará e da adequação ao contexto em que será utilizado" (CoElHo, 2008, p. 228).

\section{Interatividade}

De acordo com Kiousis (2002), as definições da Interatividade, do ponto de vista da ciência da computação e do Design, gradualmente vem sendo focadas no usuário. Ainda assim, a partir dos estudos de Kiousis, é oportuno realizar um panorama sobre as perspectivas intelectuais dos autores que debatem a Interatividade, e também do objeto que eles enfatizam ao definir seus conceitos. A partir deste panorama, fica mais clara a relação entre Design e Interatividade e qual abordagem é mais apropriada no estudo do Design de Interfaces digitais com foco na Interatividade.

Existe uma dificuldade para encontrar um consenso conceitual a respeito da interatividade (SIMS, 1997; MORAES, 1998; JENSEN, 2005; FERRERA, 2008), pois o padrão que faz uma mídia ser mais interativa que a outra é ambíguo (KIOUSIs, 2002).

Para Sundar (2004), Interatividade é um atributo da tecnologia e não do usuário, pois se uma pessoa tem habilidades adequadas para usar uma interface específica, ela pode ser avaliada como muito interativa. Se o usuário não tem habilidades, pode ser classificado como muito pobre. O autor conclui, então, ser provável que um sistema de realidade virtual - que requer habilidades avançadas - ser classificado com interatividade baixa em comparação com uma aplicação usável e usada diariamente, como o e-mail. Assim, muitos confundem interatividade percebida com a usabilidade do sistema.

Para Rafaeli (1988), a Interatividade apresenta relações diretas com o contexto comunicacional, como os relacionamentos por mensagens ou canais. Para este autor, o foco está na comunicação entre os usuários e a interatividade é um atributo desse processo, e não da tecnologia que o está mediando. Observa-se, então, contrapontos nos conceitos sobre Interatividade e este fato se repete em muitos outros conceitos de outros autores.

A fim de categorizar os diversos conceitos e capturar a preponderância do trabalho conceitual e empírico sobre a Interatividade, Kiousis (2002) gerou uma ferramenta organizacional básica e simples, que foi adaptada para a Figura 4. O autor fez um panorama vasto e criterioso, ao citar uma série de autores da década de 1980, 1990 e do início dos anos 2000. Dentre eles, está Rafaeli (1988), Steuer (1992), Jensen (1998), Heeter (1989, 2000), Ha e James (1998), Downes e McMillan (2000). 

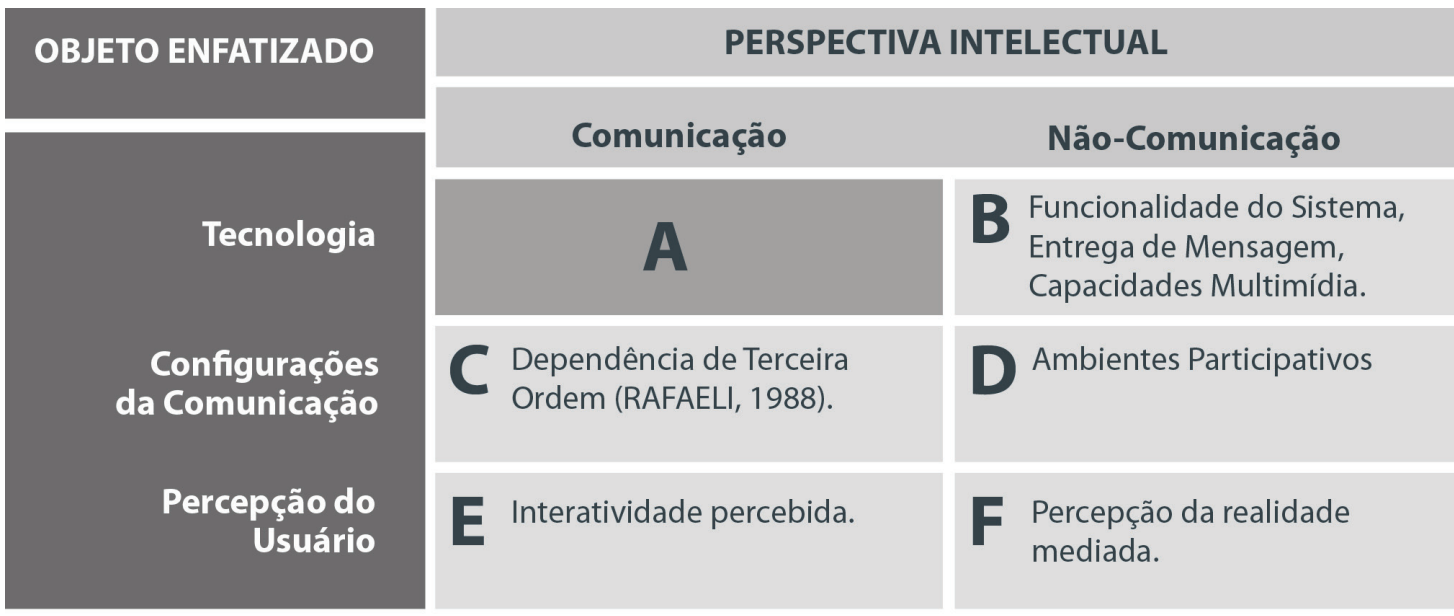

A Velocidade, Alcance, Mapeamento, habilidade do sistema para facilitar influência do usuário, Complexidade de Escolha, Flexibilidade de Tempo, etc.

Autores destacados: Steuer (1992), Durlak (1996), Jensen (1998), Heeter (2000), Ha and James (1998).

Figura 4. Gráfico embasado na Ferramenta Organizacional de Kiousis (2002)

Em concordância com a Figura 4, determina-se que os conceitos sobre interatividade são divididos em duas perspectivas intelectuais: Comunicação (Communication) e Não-Comunicação (Non-Communication). Existem, também, três objetos de estudo enfatizados: Tecnologia, Configuração da Comunicação e Percepção do Usuário.De forma geral, a maioria da literatura sobre a Interatividade tratada na obra de Kiousis, toca em, pelo menos, um destes três objetos. A maioria dos autores que ele tratou segue a perspectiva intelectual da Comunicação, porém, uma parcela menor defende a teoria da Não-Comunicação. Ainda que este trabalho siga a perspectiva da Comunicação, enfatizando a tecnologia como objeto de estudo, um breve levantamento sobre a Não-Comunicação contribui para fundamentar tais escolhas. Ela é, então, caracterizada pela Comunicação Face a Face, que é um padrão para justificar experiências interativas. É fundamentada a partir da Psicologia e Sociologia, tendo como foco as relações humanas, ainda que existam relações entre humanos e máquinas. Turkle (2005) sugere que, nessa perspectiva da Não Comunicação, os seres humanos atribuem características humanas aos sistemas computacionais. Para aqueles que favorecem a tecnologia ao definir a Interatividade, como Kiousis (2002), a Comunicação Face a Face é problemática, pois a maioria das experiências interativas é associadaàambientes de mediaçãoo tecnológica. Mesmo que os estudos sobre Interatividade estejam mais relacionados com as novas tecnologias, a Comunicação Face a Face continuou a ser empregada, porém, a partir do termo Comunicação Interpessoal (KIOUsıs, 2002). Há, então, uma facilidade na aplicação dessa expressão, porque ela ocorre tanto na mediação tecnológica 
quanto em contextos não mediados. Independente da perspectiva usada ou do objeto de estudo enfatizado, Kiousis (2002) encontrou em sua pesquisa (literatura acadêmica) alguns pontos relevantes:

- A abordagem de cada autor estudado apresenta uma preocupação equivalente entre a estrutura da mídia e as características humanas.

- A maioria dos autores foca nas variáveis da Interatividade, esteja essa relacionada com a estrutura tecnológica, comunicação ou percepção do usuário.

- Com o crescimento das novas mídias, mais deliberações conceituais sobre interatividade foram necessárias na década de 1980. E, considerando os demais autores citados nesse artigo e citados, também, na obra de Kiousis, a década de 1990 também foi fundamental na definição sobre interatividade integrada às novas mídias. Tais percepções justificam o fato da Interatividade estar intimamente associada à tecnologia.

A partir dos pontos levantados, e referentes à obra de Kousis (2002), ele ainda observa que, ao combinar aspectos convincentes da discussão sobre Interatividade a partir dos campos da Comunicação, Sociologia, Psicologia, Computação e Design é possível identificar a verdadeira natureza do conceito.

Com isso, o autor mescla os principais atributos apresentados nos conceitos dos autores tratados em seu trabalho e cria uma definição própria sobre Interatividade:

Interatividade pode ser definida como o grau em que participantes podem se comunicar (um para um, um para muitos, muitos para muitos), tanto sincronamente quanto assincronamente e participar em trocas de mensagens recíprocas (dependência de terceira ordem). No que compete a usuários humanos, isso refere-se, adicionalmente, a suas habilidades de perceber a experiência como uma simulação da comunicação interpessoal e aumentar a sua consciência da telepresença (KIOUSIs, 2002, p. 372, tradução nossa).

Em relação ao conceito apresentado, cabe ressaltar que o termo Tecnologia da Comunicação diz respeito a qualquer produto, do telefone a um sistema computacional. Ambiente mediado é qualquer produto, do telefone sem fio à realidade virtual. Comunicação trata da transferência de uma simples informação a movimentos sofisticados em videogames ou pela www, envolvendo caminhos comunicacionais lineares ou não lineares. As relações 
entre participantes podem ser as relações entre humanos, entre máquinas ou entre humano e máquina. Telepresença é a habilidade de uma mídia de formar um ambiente que, na mente dos participantes da comunicação tenha precedência sobre ambientes reais (steuer, 1992).

Dessa forma, entende-se que, mesmo que estas definições tenham sido apresentadas há uma década, e que tenham sido embasadas em autores da década de 1980 e 1990, os conceitos sãoplausíveis e coerentes com a tecnologia existente hoje.

A Figura 5 é uma estrutura adaptada de Kiousis (2002), a qual define os três objetos de estudo sobre Interatividade. $\mathrm{O}$ autor ainda ressalta que cada objeto da figura pode ser utilizado separadamente para analisar uma tecnologia ou pode ser usado em conjunto.

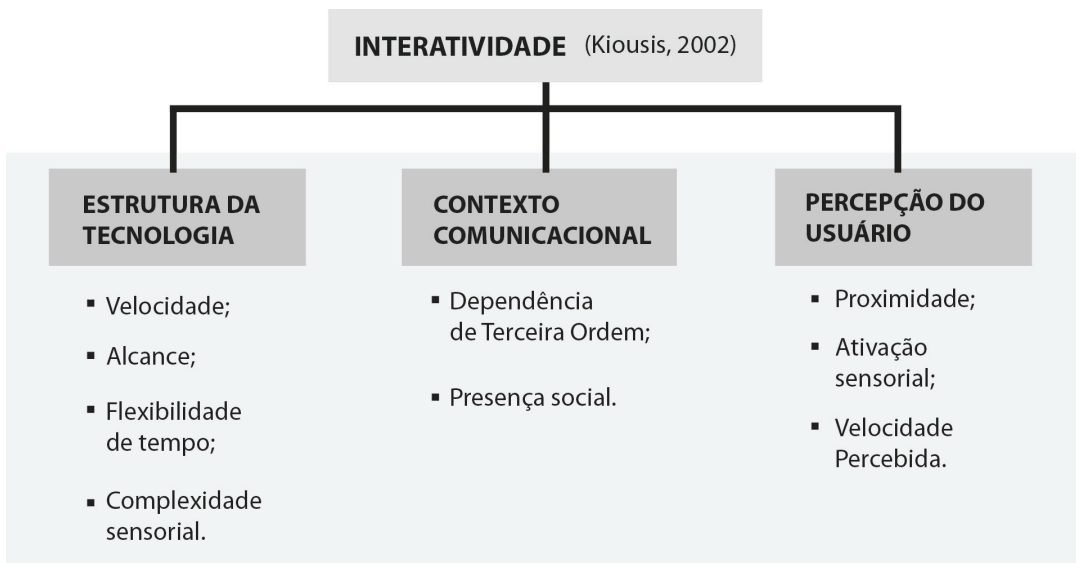

Figura 5. Ilustração com estrutura sobre o conceito de interatividade adaptado de Kiousis (2002)

A estrutura da Figura 5 é embasada em diversos autores. Steuer (1992) e Jensen (1998) são alguns deles e, ainda que não apresentem uma mesma forma de pensar a Interatividade (Kiousis, 2002), ambos tem a perspectiva de que ela está atrelada à tecnologia.

Jensen (1998) propôs que a Interatividade é a medida da habilidade potencial de uma determinada mídia de permitir que o usuário exerça influência sobre o conteúdo ou forma da comunicação mediada. Steuer (1992), alguns anos antes, propôs que a interatividade refere-se ao grau em que usuários de uma mídia podem influenciar a forma ou o conteúdo de um ambiente mediado. A visão desses autores é focada na propriedade do ambiente mediado e na relação entre indivíduos com esse ambiente. Para Steuer (1992) três fatores contribuem para a interatividade: 
- Velocidade: refere-se à taxa a qual uma entrada pode ser assimilada no ambiente mediado.

- Alcance: refere-se ao número de possibilidades para uma ação a qualquer momento.

- Mapeamento: refere-se à habilidade do sistema de mapear seus controles para mudar o ambiente mediado de uma forma natural e previsível.

Tanto velocidade quanto Alcance são destacados na estrutura da Figura 5. O Alcance da Interatividade é determinado por um número de atributos do ambiente mediado que pode ser manipulado e pela quantidade de variação possível dentro de cada atributo. Esse fator refere-se, também, à quantidade de mudanças que podem ser efetuadas no ambiente mediado.

De acordo com Steuer (1992) quanto maior o número de parâmetros/ atributos que podem ser modificados, maior o alcance de Interatividade de uma mídia. Batista (2008) propõe uma série de elementos interativos (apresentados no Item 3) de uma interface digital que apresentam ligação com o fator Alcance. Os elementos interativos, então, seriam os parâmetros específicos que podem ser modificados e, quanto maior o número deles, maior seria o alcance de interatividade da mídia.

Ao considerar a ligação que a interatividade tem com a tecnologia e cada vez mais, com os usuários, além da contribuição de outros autores a respeito do tema tratado, Kiousis (2002) propõe que a Interatividade, como uma "qualidade da mídia”, pode ser vista na forma, conteúdo e estrutura da tecnologia e sua relação com o usuário.

\section{Relações entre interatividade e design de interface}

Algumas abordagens referentes aos dois eixos teóricos tratados - Interatividade e Design - apresentam conceituações complementares. Ao passo em que a Interatividade, como qualidade da mídia, pode ser vista na forma, conteúdo e estrutura da tecnologia e sua relação com o usuário, o Design tem como objeto de estudo a forma, sua atividade é a informação, composta e apresentada como objeto e tendo como finalidade o produto. Infere-se, assim, que a Interatividade, como tópico da comunicação digital, é um elemento que faz parte da atividade do Design e deve ser estruturado e aplicado a partir de seus preceitos.

Como justificativa desta primeira consideração, observa-se que a Interatividade apresenta-se como forma, conteúdo e estrutura em uma interface digital. O Design estuda, compõe a forma, organizando a informação (conteúdo), com o intuito de apresentar um produto estruturado e satisfatório. 
Considerando, também, a relação dos dois termos com os usuários, sugere-se que ambos convergem para um mesmo ponto. A Interatividade tem uma relação direta com o usuário, bem como o Design é orientado à interação entre usuário e artefato que, nesse caso, é a Interface Gráfica do Usuário. Dessa forma, sendo a Interatividade uma qualidade variável da interface, o Design se apropria de seus estudos e variáveis para conceber, projetar, planejar e configurar sistemas de informação.

A Interatividade também refere-se ao grau em que participantes se comunicam, ou seja, ao grau em que o usuário e o sistema interagem. A Interatividade é, então, o grau de interação existente em uma interface; é o potencial interativo que um sistema pode oferecer. Nesse contexto, entende-se por "grau", os níveis de uma determinada medida ou uma determinada grandeza que serve de padrão para avaliar outra.

Nessa mesma linha de pensamento, o Design de Interfaces tem como foco principal facilitar a interação entre usuário e artefato ou fornecer uma interação apropriada entre os dois, a partir do domínio da interface. Se o Design é orientado à interação e a Interatividade é a medida de interação de uma interface, então este torna-se um componente essencial daquele. A Interatividade, assim, é capaz de se tornar o elemento central na criação de uma ferramenta de mensuração do potencial interativo de ambientes virtuais.

Considerando o Design uma atividade sistemática, que concebe, projeta, planeja e configura sistemas de informação, deduz-se que essa é uma atividade apropriada para conceber e projetar uma ferramenta de mensuração da interatividade de interfaces digitais.

A Interface Gráfica do Usuário é o ponto de interconexão entre usuário e tecnologia. Os usuários, por sua vez, têm o controle das diversas funções de uma interface, graças aos elementos interativos. A Interatividade, então, favorece a comunicação nestes ambientes e, tanto quanto o Design, é comunicação e informação.

Sugere-se, também, que a Usabilidade seja o envoltório da Interatividade, pois está ligada à produtividade na interação entre usuário e computador. Dentre outros tópicos, é graças ao estudo da Interatividade e aplicação adequada de elementos interativos em uma interface que um ambiente virtual torna-se usável e útil. A Interatividade, então, busca adequar a forma como o usuário utiliza a interface e realiza suas tarefas.

A partir da estrutura proposta por Kiousis (2002) para categorizar conceitos sobre Interatividade, somada a alguns conceitos sobre Design de Interfaces, sugere-se a criação de uma nova categoria, a Estrutura Visual. Ela foi originada do conceito da variável Alcance, que está inserida na Estrutura Tecnológica. Essa variável é determinada por um número de atributos do 
ambiente mediado que pode ser manipulado e pela quantidade de variação possível dentro de cada atributo.

Cada elemento interativo da interface, que em conjunto contemplam a Estrutura Visual, são os atributos específicos que podem ser modificados. Quanto mais atributos modificados, maior o alcance de interatividade de uma mídia.

Ainda que os elementos interativos tenham sido relacionados com a estrutura de Kiousis a partir da variável Alcance, optou-se por criar uma nova categoria apenas para este conjunto, pois os elementos interativos da interface envolvem uma quantidade considerável de elementos, cada um com um conceito específico. Da mesma forma, todos eles são caracterizados por elementos preponderantemente visuais, o que contribui para a criação de uma nova categoria. Tais verificações definiram, como mostra a Figura 6, a criação de uma nova categoria da Interatividade que está intimamente relacionada com o Design de Interfaces e mantém a perspectiva tecnológica e comunicacional proposta neste artigo.

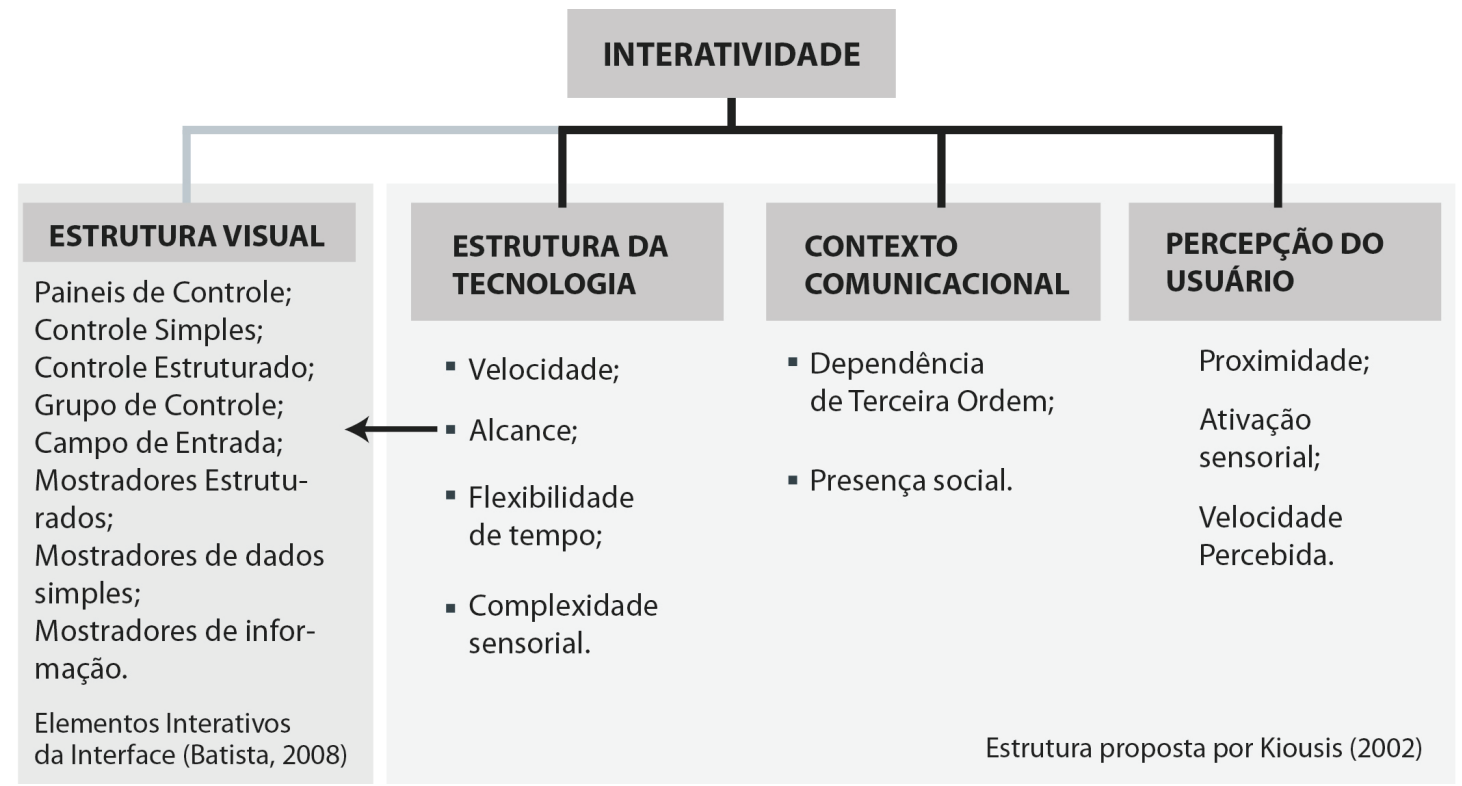

Figura 6. Relação entre elementos da interface com a estrutura conceitual da Interatividade 


\section{Conclusão}

O objetivo deste artigo foi abordar conceitos sobre Interatividade, sob uma perspectiva tecnológica e, num segundo momento, comunicacional. Conceitos fundamentais sobre Design, nessa mesma perspectiva, também foram abordados, a fim de encontrar as relações entre o primeiro e o segundo.

A revisão dos principais eixos teóricos ajudou a definir as relações fundamentais entre Interatividade e Design, facilitando o entendimento de que a Interatividade é um tópico a ser desenvolvido junto ao processo de Design de Interfaces.

Como recomendações futuras, pretende-se utilizar as variáveis referentes ao contexto tecnológico e comunicacional para avaliar a interface de um Sistema Online, que é objeto de estudo da Dissertação de Mestrado do pesquisador deste trabalho.

\section{Referências}

ALMEIDA, F. Bases Conceituais e Metodológicas para a Pesquisa Aplicada em Design, 2012.

BATISTA, C. Modelo e Diretrizes para o Processo de Design de Interface Web Adaptativa. Dissertação de Mestrado (Programa de Pós- Graduação em Engenharia e Gestão do Conhecimento) - Universidade Federal de Santa Catarina, Santa Catarina, 2008.

BEVILÁCQUA, T. S. O conceito de interface no contexto do design. $3^{\circ}$ Congresso Internacional de design da informação. 8 - 10 de outubro de 2007.

BONSIEPE, G. Del objeto a la interfase: Mutacionesdeldiseño. Buenos Aires: Ediciones Infinito, 1997.

BRAGA, A. S. Design de Interface: as origens do design e sua influência na produção da hipermídia. Dissertação (Mestrado em Comunicação e Semiótica) Pontífica Universidade Católica de São Paulo, São Paulo, 135f., 2004.

COELHO, L. A. (Org.). Conceitos Chave em Design. Ed. PuC-RIo. Novas ideias: Rio de Janeiro, 2008.

CRUZ, F. L. A Necessidade de Informação dos Projetistas de Interfaces de Sistemas Interativos na Web, com foco em Usabilidade. Dissertação de Mestrado (Programa de Pós-Graduação em Ciência da Informação), Universidade de Brasília, Brasília, 2008.

CYBIS, W. et al. Ergonomia e Usabilidade: Conhecimentos, Métodos e Aplicações. 2a Ed. São Paulo: Novatec Editora, 2010. 
DOWNES, E. J.; MCMILLAN, S. J. Defining Interactivity: A qualitative identification of key dimensions. New Media \& Society - Vol. 2 (2): 157-179, 2000. Disponível em: <http://nms.sagepub.com/content/2/2/157.full.pdf+html>. Acesso em: 19 de fevereiro de 2013.

FERREIRA, A. B. H. Miniaurélio: $\mathrm{O}$ dicionário da língua portuguesa. $7^{\mathrm{a}} \mathrm{Ed}$. Curitiba: Ed. Positivo, 2008.

HA, L.; JAMES, E. L. Interactivity Re-examined: A Baseline Analysis of Early Business Websites. Journal of Broadcasting and Eletronic Media - Vol. 42(4): 457-74, 1998. Disponível em: <http://news-business.vlex.com/vid/interactivity-reexamined-baseline-sites-52644471>. Acesso em: 19 defevereiro de 2013.

HEETER, C. Interactivity in the Context of Designed Experience. Journal of Interactive Advertising. (2000). Disponível em: <http://jiad.org/article2>. Acesso em: 7 de fevereiro de 2013.

JENSEN, J.F. Interactivity:Tracing a New Concept in Media and Communication Studies. Nordicon Review, Vol. 19: 185-204, 1998. Disponível em: <http:// www.organicode.net/jenson.pdf >. Acesso em: 19 de fevereiro de 2013.

KIOUSIS, S. Interactivity: a concept explication. New Media \& Society. Vol. 4: 355, 2002. Disponível em:<http://nms.sagepub.com/content/4/3/355.full. pdf + html $>$. Acesso em: 05 de setembro de 2012.

KRUG, S. Não me faça pensar: Uma abordagem de bom senso à usabilidade na web. Rio de Janeiro: Ed.Alta Books, 2008.

LÖBACH, B. Design Industrial: bases para a configuração de produtos industriais. São Paulo: Blücher, 2001.

MEMÓRIA, F. Design para a Internet: Projetando a experiência perfeita. Rio de Janeiro: Elsevier, 2005.

MORAES, A.; MONT’ALVÃO, C. Ergonomia: conceitos e aplicações. 4. ed. Teresópolis: 2AB, 2010.

MORAES, M. Produtos Interativos para consumidores multimídia: Discutindo a interatividade na Era dos Bits. Pré Textos (Compós). Salvador: UFBA, 1998.

PASSOS, J. E. Metodologia para o design de interface de ambiente virtual centrado no usuário. Dissertação de Mestrado (Programa de Pós-graduação em Design), Universidade Federal do Rio Grande do Sul, Porto Alegre, 2010.

PREECE, J. et al. Design de Interação: Além da interação homem-computador. Porto Alegre: Ed. Bookman, 2005. 
RAFAELI, S. Interactivity: From New Media to Communication. 1988. [Online] Disponível em: <http://gsb.haifa.ac.il/ sheizaf/interactivity/ Rafaeli_interactivity.pdf> Acesso em: 24 de agosto de 2012. Cap. 4, p. 110-134.

REDIG, J. Não há cidadania sem informação, nem informação sem design. Rev. Bras. InfoDesign | São Paulo | InfoDesign | v. 1, n. 1 (2004). [Online] Disponível em: <http://www.infodesign.org.br/revista/public/journals/1/ No.1Vol.12004/InfoDesign_v1_n1_2004_04_Redig.pdf?download=1>. Acesso em: 18 de junho de 2011.

REGINALDO, T.; PERASSI, R. Bases conceituais para a pesquisa aplicada em design: estudo a partir dos trabalhos de conclusão de curso UFSC. Design, Arte, Moda e Tecnologia. São Paulo: Rosari, Universidade Anhembi Morumbi, PUC-RIO e UNESP-Bauru, 2012. Disponível em: <http://sitios.anhembi.br/ damt/arquivos/25.pdf>. Acesso em: 13 de fevereiro de 2013.

ROCHA, H. V.; BARANAUSKAS, M. C. Design e Avaliação de Interfaces Humano-Computador. Instituto de Computação. Universidade Estadual de Campinas, 2003. [Online] Disponível em: <http://pan.nied.unicamp.br/download_livro/livrodownload.html>. Acesso em 01 de outubro de 2012.

SILVEIRA, B. et al. O Design e suas funções. XIV Simpósio de Ensino, Pesquisa e Extensão. 2010. Disponível em: <http://www.unifra.br/eventos/ sepe2010/2010/Trabalhos/tecnologica/Completo/5659.pdf >. Acesso em: 07 de fevereiro de 2013.

SIMS, R. Interactivity: a Forgotten Art?. Faculty of Education. University of Technology, Sydney. 1997. [Online] Disponível em: <http://www2.gsu. edu/ wwwitr/docs/interact/>. Acesso em: 12 de setembro de 2012.

SUNDAR, S. S. Theorizing Interactivity's Effects. The Information Society, Vol. 20: 385-389, 2004. Disponível em: <http://crx.sagepub.com/content/30/1/30.full.pdf+html>. Acesso em: 19 de fevereiro de 2013.

TURKLE, S. The Second Self: Computers and the Human Spirit Twentieth Anniversary Edition. Journal of High Technology Law. 2005. Disponível em: <http://www.jhtl.org/book_reviews/2005_2006/br_second_self_castriotta. pdf $>$. Acesso em: 22 de fevereiro de 2013.

PORTO EDITORA. Aplicativo para Ipad. Acesso em 14 de dezembro de 2012. 
Recebido em: 08/04/2013

Aceito em: 01/05/2013

\section{Como citar}

BORTOLÁS, N. O. Uma abordagem sobre os conceitos de interatividade e sua relação com o design. Arcos Design. Rio de Janeiro: PPD ESDI - UERJ. Volume 7 Número 1 Junho 2013. pp. 81-101. Disponível em: [http://www.e-publicacoes.uerj.br/ index.php/arcosdesign]

\section{DOI}

10.12957/arcosdesign.2013.9996

\section{(c) (i) (2)}

A Revista Arcos Design está licenciada sob uma licença Creative Commons Atribuição - Não Comercial - Compartilha Igual 3.0 Não Adaptada. 